\title{
BIONIS Network Prize Award
}

We have a winner! New prize to develop biomimetics research awarded.

The career development of a promising biomimetics researcher has just been boosted by the award of the First BIONIS Biomimetics Award.

Biomimetics - the discipline of looking to nature for inspiration for new technologies and designs - is rapidly yielding new commercially successful technologies.

Self-cleaning paint, novel adhesives, robots, medical devices, pharmaceuticals and self-healing materials have all recently been launched and are being rapidly taken up by consumers.

Dr Carlo Menon, 29, from Rovigo in Italy, was awarded the prize, in the face of stiff competition from a field of high-quality applicants from around the world. He will shortly to take up a new position at Simon Fraser University in Vancouver, Canada.

The prize of $£ 5,000$ — sponsored by Swedish Biomimetics $3000 \circledR$ — will be spent by Dr Menon to conduct visits to a number of internationally-renowned research centres for biomimetics research in North America and Europe.

Dr Menon said: "I am honoured to receive the BIONIS award. It gives me a great opportunity to collaborate with renowned scientists in Biomimetics and acquire knowledge to start up a new successful laboratory.

"The prestige of the BIONIS award will undoubtedly enhance the credibility of the interdisciplinary research that I am promoting and will help me to expand the biomimetic network".

Lars-Uno Larsson, founder and CEO of Swedish Biomimetics $3000 \circledR$ said: "We were very impressed by the international response to this, the 1st BIONIS Biomimetics Award and were equally pleased that the Award winner's plans so exactly match the ethos behind the award."

Dr Menon will undertake his visits during summer 2007 and present an invited lecture on his activities at the prestigious Bath Royal Literary and Scientific Institution on Thursday 20th September, 2007. He winner will experience other research and development environments and strengthen links between his organisation and others around the world. Hosts will benefit from the participation of a leading researcher in their organisation.

\section{About BIONIS Network}

The BIONIS network was set up in spring 2002 by Prof. George Jeronimidis, Prof. Julian Vincent and Phil Sheppard. Membership is now over 300, with members from academia and industry in more than 40 countries. The mission of the network is to promote the application of Biomimetics in products and services and its use in education and training. It is currently supported by Swedish Biomimetics $3000 \AA$ and hosted by the University of Reading.

Swedish Biomimetics $3000 \AA \mathrm{AB}$ is a VPO focussed on Biomimetics. Its mission is to fund translational research of Biomimetic concepts to the point where they are considered commercial candidates.

Further details may be found at the BIONIS website (www.biomimetics.org.uk) or obtained by email from bionis@reading.ac.uk

For media information contact Lucy Ferguson, Senior Press Officer, at: L.Ferguson@reading.ac.uk 